\title{
Comparison of the Effectiveness of Mindfulness-Based Cognitive Therapy and a Quality of Life-Based Therapy on Rumination in Patients With Migraine
}

\author{
Mohammad Shabani ${ }^{1}$, Hamid Nejat ${ }^{2 *}$, Mohammad Reza Saffarian ${ }^{1}$ \\ 'Department of Education Sciences, Mashhad Branch, Islamic Azad University, Mashhad, Iran \\ ${ }^{2}$ Department of Psychology, Quchan Branch, Islamic Azad University, Quchan, Iran
}

\author{
*Correspondence to \\ Hamid Nejat, \\ Department of Psychology, Guchan \\ Branch, Islamic Azad University, \\ Guchan, Iran. \\ Tel: +989155141796 \\ Email: hnejat54@yahoo.com
}

Received October 14, 2018 Accepted December 22, 2018 Published online June 30, 2019
Please cite this article as follows: Shabani M, Nejat H, Saffarian MR. Comparison of the effectiveness of mindfulness-based cognitive therapy and a quality of life-based therapy on rumination in patients with migraine. Int J Basic Sci Med. 2019;4(2):61 68. doi:10.15171/ ijbms.2019.13.

\begin{abstract}
Introduction: The effects of mindfulness-based cognitive therapy and quality of life-based therapy on rumination were compared in patient with migraine. The present study also investigated the effectiveness of quality of life-based therapy and mindfulness-based cognitive therapy.

Methods: This quasi-experimental study with 3 (2 experimental and one control) groups was carried out with pretest-posttest design. The study population consisted of all patients with migraine headache referring to Torbat Heidarie hospitals and clinics from June to July 2018 . The samples were 45 patients who were selected by random sampling and then randomly allocated to 2 experimental groups and one control group each with 15 members. One experimental group underwent mindfulness-based cognitive therapy and the other received quality of lifebased therapy. The control group received no intervention. Research instruments were Ahvaz Migraine Questionnaire and Huksema and Maro's Ruminative Response Scale. The tools were filled out by the participants before and after the interventions. The data was analyzed in SPSS version 22.

Results: The mindfulness-based cognitive therapy and quality of life-based therapy significantly improved rumination in patients with migraine. In addition, the effectiveness of the 2 interventions was not significantly different.

Conclusion: The educational interventions based on modifying basic cognitions, replacing negative intrusive thoughts with positive thoughts, and avoiding and neutralizing intrusive thoughts through mindfulness-based cognitive methods and interventions based on improving quality of life resulted in a substantial improvement of rumination and frequent intrusive thoughts. Indeed, changes in cognitive reactions to pain and altering beliefs and expectations are the main mechanisms for improving headache.

Keywords: Mindfulness-based cognitive therapy, quality of life-based therapy, rumination
\end{abstract}

\section{Introduction}

Headache is the most prevalent neural symptom and one of the main human ailments. Migraine headache is a specific invasive disorder with one side headaches with or without visual or gastrointestinal problems (e.g. nausea, vomiting, and photophobia). One possible cause of the headache is pressure on the cerebral blood flow. ${ }^{1}$ In fact, migraine is considered as a sensory processing disorder of the central nervous system. The neuronal structures that contribute to migraine development include the cerebral cortex and brainstem. ${ }^{2}$ Overall, migraine is of 2 types; migraine without aura and migraine with aura. ${ }^{3}$ The former is the most common migraine vascular headache that affects over $80 \%$ of migraine patients. The latter, also known as classic migraine, is the less common type and accounts for $15 \%-20 \%$ of migraine cases. The difference between the classic migraine and migraine without aura is that in the classic migraine, the patients experience a series of neural disorders (e.g. appearance of illuminous spots and paresthesia). ${ }^{4}$ Migraine can also be associated with physical fatigue, emotional stress, depression, and other psychological events. ${ }^{5}$ Migraine headache may influence

(c) 2019 The Author(s); Published by Zabol University of Medical Sciences. This is an open-access article distributed under the terms of the Creative Commons Attribution License (http://creativecommons.org/licenses/by/4.0), which permits unrestricted use, distribution, and reproduction in any medium, provided the original work is properly cited. 
the patients' occupational and social/private life by exerting negative effects on their quality of life. ${ }^{6}$ Recent studies have shown that migraine increases the risk of cardiac diseases and hypertension. ${ }^{7}$ In addition, psychological problems are common among patients with chronic headache, so that a comparatively higher proportion of patients with migraine headache also suffer from depression and anxiety disorders. ${ }^{8}$

One of the prevalent patterns of migraine headaches is associated rumination defined as frequent intrusive thoughts. ${ }^{9}$ Abdullahi reported a relationship between rumination and migraine. ${ }^{10}$ Rumination refers to the thoughts that tend to be repetitive and conscious and focus on a specific subject; they even appear in the absence of immediate and essential environmental stimuli. ${ }^{11}$ Papageorgiou and Wales showed that rumination is a long chain of repetitive, rotating, and self-centered thoughts and a response to primary negative thoughts. ${ }^{12}$ The cognitive theory recommends that disastrous interpretation in the area of intrusive thoughts leads to the occurrence and persistence of such thoughts. Comprehensive analyses show that stimulus intrusive thoughts trigger specific automatic types of thoughts. According to this theory, an intrusive thought leads to mood disorder so that individual beliefs system finds the intrusive thoughts to be unacceptable and consequently trigger negative automatic thoughts. ${ }^{10}$ Researches have shown that ruminative thoughts in response to painful experiences prolong and intensify depressed mood periods. In addition, rumination negatively tilts one's thoughts so that an individual suffering from rumination tends to have lower problem-solving capability. ${ }^{12}$

Several studies have focused on the biological, environmental, psychological and social factors effective on the development of headaches. The results have supported a relationship between psychological and personality factors and migraine headaches. ${ }^{13}$ Kolotylo and Broomi reported that chronic pains explained 69\% of variance in disability in women with migraine. ${ }^{14}$ Moreover, depression, migraine headache, and chronic pain explained $8.64 \%$ of the variance in quality of life in individuals with migraine. Since the late 1970s, psychological treatments for headache have drawn much attention. The findings have also highlighted the effectiveness of non-pharmacological cognitive and psychological methods for headache treatment. ${ }^{15-17}$

Psychotherapeutical improvement of quality of life is a novel approach in positive psychology that includes continuous integration of cognitive therapy and positive psychology. It is consistent with Beck's latest arrangement of cognitive therapy and cognitive theory of depression and psychopathology. ${ }^{18}$ The quality of lifebased therapy is an approach to improving happiness. It is recommended for both clinical and non-clinical service providers. ${ }^{19}$ It addresses and emphasizes different aspects of life, prevention, improvement of mental health, and marital satisfaction, so that it is one of the best approaches to improving quality of life. ${ }^{20}$ The treatment aimed to improve the quality of life is based on a 5-pillar pattern including living condition, attitudes, standards of fulfillment, importance, and overall satisfaction (CASIO). ${ }^{21}$ This therapeutic method follows the approach of life satisfaction, where the skills and principles needed by the help seeker to identify and follow the needs, goals, and wishes are taught in 12 key and valuable fields of life. The fields covered in this approach are hygiene and physical health, self-respect, values and goals, work, money, game, learning, creativity, helping others, love, friends, relatives, home, neighbor, society, spouse, and life in general term. ${ }^{18}$ The objective of quality of lifebased therapy is to improve professional self-care or inner enrichment, and to prevent depression. ${ }^{19}$

Another development was the introduction of a new approach by Teasdale et al, which was based on interactions of cognition, emotion, and the mind. ${ }^{22}$ Their work led to a therapeutic cognitive approach based on mindfulness. The mindfulness-based cognitive therapy was a great advancement toward codifying the cognitive behavioral therapeutic approach. Teaching mindfulness entails meta-cognition learning and new behavioral strategies to concentrate and avoid rumination and tendency to worrying responses, leading to expansion of new thoughts and attenuation of unwanted emotions. Mindfulness means paying attention in a specific and purposeful manner at the moment and without judgement. ${ }^{13}$ According to Kabat-Zinn, mindfulness is moment-bymoment judgmental awareness. In his 1994 definition of mindfulness, Kabat-Zinn highlighted paying attention to immediate goals in a specific and non-judgmental manner. Finally in 2003, he defined mindfulness as a type of awareness that is developed through paying attention to real goals, seizing the moment, and without any judgement about the evident, moment-by-moment experiences. ${ }^{23}$ Mindfulness meditation activates an area of the brain that creates positive emotions and exerts useful effects on the body immune system. ${ }^{24}$ Reibel et al reported that mindfulness was effective on attenuation of stress and treatment of physical and mental symptoms in individuals with chronic pains. ${ }^{25}$ Given the above mentioned and the paucity of similar studies in Iran and other countries, especially on the quality of life-based therapy and mindfulness-based cognitive therapy, and their effects on migraine headache and rumination, we aimed to compare the effects of these 2 therapeutic approaches on rumination in patients with migraine.

\section{Methods}

Study Population

This was a quasi-experimental study with preintervention/post-intervention design included 3 (2 experimental and one control) groups. Rumination was the dependent variable that was measured in the all 
studied groups before and after implementation of the interventions (mindfulness-based cognitive therapy and quality of life-based therapy).

Study population consisted of all patients with migraine headache referring to hospitals and clinics in Torbat Heidarieh, northeast of Iran from June to July 2018. First, all the candidates were briefed about the research. Then the individuals interested in participation in the study were asked to fill out a consent form. The sample size $(n=45)$ was determined based on Cohen's table (1992) (test power $=0.80, a=0.05$, effect size $=08$ ). The participants were randomly selected and allocated to 2 experimental groups and one control group $(n=15)$.

\section{Inclusion Criteria}

The inclusion criteria were volunteering to participate in the study, education level from high school diploma to bachelor's degree, definite diagnosis of migraine by a specialist, at least 5-year history of migraine attacks, duration of migraine attacks from 4 to 72 hours, one sided headache attack, pulse headache, moderate to severe pain, having headache when climbing stairs or doing similar activities, nausea and vomiting, and photophobia and phonophobia or either of them.

\section{Exclusion Criteria}

The exclusion criteria were psychological, neurological or other major medical conditions, severe physical diseases, drug addiction or abuse, and a chronic physical disease.

\section{Research Instruments}

Ahvaz Migraine Headache

The Ahvaz Migraine Headache (AMQ) was designed and validated by Najjarian et al. ${ }^{26}$ It consists of 25 items and was developed with participation of 382 students at Shahid Chamran University of Ahvaz and Islamic Azad University of Ahvaz. The items are rated on a 4-point Likert scale (never $=1$, rarely $=2$, sometime $=3$, and most of the time $=4)$. Najjarian et al reported the reliability and internal consistency of the instrument as being 0.8 and 0.91, respectively. Shirzadi Bestoni et al assessed the validity of the questionnaire by comparing it with the Hospital Anxiety and Depression Scale (HADS), hysteria, hypochondria, anxiety subscale, short form of Minnesota Multiphasic Personality Inventory (MMPI), and Ahvaz Aggression Scale and obtained the correlation coefficients $0.49,0.34,0.36,0.49$, and 0.46 , respectively $(P<0.05){ }^{27}$ Najjarian et al also calculated the correlation coefficient (r) of the AMQ at 0.50 using Ahvaz Perfectionism Scale $(P<0.001)$.

\section{Ruminative Response Scale}

The Ruminative Response Scale (RRS) was developed by Hoksma and Maro to measure negative mood reactions. The instrument consists of 2 subscales rumination responses and distraction responses, each of which was investigated by 11 items. The 22 items of this scale are rated on a 4 -point Likert scale (from $1=$ never to 4 $=$ often). Bagherinejad et al calculated the reliability of the instrument at 0.90 for the whole tool and at 0.92 and 0.89 for the subscales using Cronbach alpha coefficient. ${ }^{28}$ The validity of the questionnaire ( $r$ ) was calculated by correlation with metacognitive beliefs questionnaire at $0.65(P<0.001)$ (i.e. high validity level). Tabibzadeh and Sepehrian Azar obtained the reliability of the instrument to be 0.80 using Cronbach alpha coefficient. ${ }^{29}$

\section{Methodology}

After obtaining the required permissions from the research department and making necessary coordination with the hospital and clinics officials, 45 patients with migraine were randomly selected. Afterward, they were assigned randomly to 3 (2 experimental and one control) groups of 15 each. One experimental group received therapeutic intervention based on improvement of quality of life and the other experimental group received mindfulness-based cognitive therapy (Table 1). The control group received no intervention. Before and after the intervention, the participants filled out the research instruments.

\section{Data Analysis}

The data was analyzed using descriptive statistics (median, mean, and standard deviation) and inferential statistics (ANCOVA and independent samples $t$ test) in SPSS version 22.

\section{Results}

Sixteen participants (35.6\%) were men and 29 ones $(64.4 \%)$ were women. The age range of the participants was $22-42$ years old with the mean age of $32.22 \pm 5.73$ years. In addition, 20 participants (44.4\%) were 22-29 years old, 20 participants (44.44\%) were $30-39$ years old, and 5 participants $(11.1 \%)$ were $40-42$ years old. Descriptive indices of rumination were measured at pretest and posttest stages for the control and experimental groups. Based on the results, the mean score of rumination in the mindfulness-based cognitive therapy group decreased by 12 points (from 52.8 to 40.8 ) at the posttest stage; the mean score of rumination in the quality of life-based therapy group decreased by 9.26 points (from 54.33 to 45.07 ) at the posttest stage. The same score increased by 4.33 points in the control group (from 53.07 to 57.4 ) at the posttest stage. Regarding the components of rumination, the findings indicated differences in the mean scores at pretest and posttest stages between the experimental groups and the control group (Table 2).

Hypothesis 1: Mindfulness-Based Cognitive Therapy Is Effective on the Elements of Rumination in Patients With Migraine.

To test the hypothesis, MANCOVA was used so that first, the homogeneity of covariance-variance matrices 
Table 1. Content of the Education and Treatment Sessions

\section{Session Mindfulness-Based Cognitive Therapy}

Determining an approach taking into account confidentiality of peoples' life information, inviting the participants to

1 introduce themselves, body inspection practice, assigning homework, discussion and determining weekly schedule of sessions, handing out pamphlets

Relaxation training for 14 muscle groups including arm, elbow, Triceps surae muscle, femoris muscle, stomach, chest, shoulders, neck, eyes, and forehead.

Relaxation training for 6 groups of muscles including hands, arms, femoris, stomach and chest, forehead, and lips and assigning relaxation homework.

Introducing the participant to mindfulness, inhale/exhale technique, relaxation without thinking about anything else, respiration observation technique, and mindfulness practice at home before sleep.

Teaching the technique of paying attention to body movements while breathing, concentration on body limbs, searching for physical senses, assigning homework about mindfulness

Teaching attention to the mind, positive/negative thoughts, desired and undesired nature of thoughts, allowing negative and positive thoughts to the mind, throwing thoughts out of the mind without judging them or delving deeply into them.

7 Meditation, revising homework and practicing how to see the relationship between activity and mood.

Planning for the future and using the technique of paying attention to the moment for the rest of life, generalizing

the technique to the whole life. Reviewing the course and discussing the techniques and practices that the patient is not going to follow. Motivating the participants to continue the practices by finding positive reasons for doing so.

\section{Quality of Life-Based Treatment}

Defining the role of quality of life in personal life and introducing treatment based on quality of life and the new therapeutic approach in psychology. Teaching 5-pillar CASIO model and determining the headlines and general structure of sessions, determining quality of life profile for individuals and reaching an agreement on the key fields of the 16 fields of quality of life-based treatment; collecting feedbacks.

Determining agenda and examining the role of variables effective on mental health, determining self-respect based on the treatment model and teaching and assigning "success note" homework and the 2 nd way of success in achieving selfrespect ("don't ask please!!"), the 3rd way of success to achieve self-respect (selfacceptance path), the 4th way of success to achieve self-respect (profitable social relationships), the 5th way of success to achieve self-respect (helping others), teaching BATa technique to practice at home, teaching how to use "abilities list", and collecting feedbacks

Determining agenda and a short review of the previous sessions, checking homework assignments, defining health based on the treatment protocol, defining the relationship among mental health, happiness, and physical health, surveying unhealthy habits and receiving feedbacks.

Determining agenda and a short review of the previous session, checking homework assignments, introduction to the role of goals, values, and spiritual life in life satisfaction, discussing the philosophy of life, practicing goal finding, teaching life drama technique, advantages of religious and spiritual functions, an introduction to the principles of determining goals, and collecting feedbacks.

Determining agenda, short review of the previous session, checking homework assignments, determining relationship in the treatment protocol, teaching the main ideas of communication in the quality of life-based treatment

Teaching the skills to improve satisfaction with communication, letter writing $1 \& 2$, introduction to and teaching sensations dictionary, and collecting feedbacks

Determining agenda, short review of the previous session, checking homework assignments, defining learning in the treatment based on quality of life, teaching the 5 skills of improving learning (in desire environment), teaching, studying and learning skills, and collecting feedbacks.

Determining agenda, short review of the previous session, checking homework assignment, teaching the difference between "must and wanting activity" and what is playing and having fun? Determining the games that ruin quality of life. Examining the relationship between happiness and having fun, the effective steps to establish playing and having fun habits. Training and assigning homework of the list of games to be practiced at home and collecting feedback.

a Pay attention to blessings.

${ }^{\mathrm{b}}$ It is a narrative therapy technique.

was investigated. According to Box's $M$ test, $P$ value was $>0.05$, i.e. covariance matrix was homogenous (Table 3 ). As listed in Table 4, $P$ value was $<0.05$ and $\mathrm{f}_{(3,34)}$ was 4.05 , which indicates the effectiveness of the intervention on the components of rumination at posttest stage $\left(\eta^{2}=0.32\right)$.

ANCOVA test (Table 5) indicated that the mean scores of distraction, contemplation, and lost in thoughts at posttest stage significantly decreased in the mindfulnessbased therapy group in comparison with the control group.
The results of ANCOVA showed that after removing the effect of pretest, mindfulness-based cognitive therapy was significantly effective on distraction $\left(P<0.05, \mathrm{f}_{(1,}\right.$ $\left.{ }_{29)}=9.29\right)$ and its effect was equal to 0.27. Regarding contemplation, the effect of mindfulness-based cognitive therapy was significant on the posttest scores $\left(P<0.05, \mathrm{f}_{(1,}\right.$ 29) $=8.41)$ and the effect size was equal to $0.25\left(\eta^{2}=0.25\right)$. Regarding the component lost in thought, the effect of mindfulness-based cognitive therapy was significant at posttest $\left(P<0.05, \mathrm{f}_{(1,29)}=11.31\right)$ and the effect size was 
Table 2. Descriptive Indices-Pretest and Posttest Scores of Rumination and its Components

\begin{tabular}{lccccc}
\hline \multirow{2}{*}{ Variable } & \multirow{2}{*}{ Test Type } & \multicolumn{2}{c}{ Experimental Group } & \multicolumn{2}{c}{ Control Group } \\
\cline { 3 - 6 } & & Mean & SD & Mean & SD \\
\hline \multirow{2}{*}{$\begin{array}{l}\text { Total rumination } \\
\text { score }\end{array}$} & Pretest & 52.8 & 8.09 & 53.07 & 13.17 \\
& Posttest & 40.8 & 13.45 & 57.4 & 17 \\
\multirow{2}{*}{ Distraction } & Pretest & 28.13 & 6.27 & 28.13 & 8.76 \\
& Posttest & 21.87 & 8.75 & 29.93 & 10.6 \\
Contemplation & Pretest & 12.8 & 2.34 & 12.33 & 2.69 \\
& Posttest & 9.67 & 4.05 & 13.8 & 4.35 \\
\multirow{2}{*}{ Lost in thought } & Pretest & 11.87 & 2.53 & 12.6 & 3.85 \\
& Posttest & 9.27 & 3.81 & 13.67 & 3.26 \\
\hline
\end{tabular}

Table 3. The Box's M Test Results on the Homogeneity of CovarianceVariance Matrices

\begin{tabular}{lcccc}
\hline Box's M & $\boldsymbol{F}$ & $\boldsymbol{d f}(\mathbf{1})$ & $\boldsymbol{d f}(\mathbf{2})$ & $\boldsymbol{P}$ \\
\hline 3.887 & 0.572 & 6 & 5680.302 & 0.753 \\
\hline
\end{tabular}

Table 4. The MANCOVA Results on the Effect of Mindfulness on the Components of Rumination

\begin{tabular}{llllllll}
\hline Test & $\begin{array}{l}\text { Source of } \\
\text { Variation }\end{array}$ & Value & $\boldsymbol{F}$ & $\boldsymbol{d f}^{\mathrm{a}}$ & $\boldsymbol{d} \boldsymbol{f}^{\circ}$ & $\boldsymbol{P}$ & Size of Effect \\
\hline $\begin{array}{l}\text { Wilks } \\
\text { lambda }\end{array}$ & Group & 0.654 & 4.052 & 3 & 23 & 0.019 & 0.346 \\
\hline
\end{tabular}

${ }^{\mathrm{a} A s s u m e d ;}{ }^{\mathrm{b}}$ Error.

Table 5. The ANCOVA Results on the Effect of Mindfulness on the Elements of Rumination

\begin{tabular}{llcccc}
\hline & Variable & $\begin{array}{c}\text { Square } \\
\text { Sum }\end{array}$ & $\boldsymbol{F}$ & $\boldsymbol{P}$ Value & Effect Size \\
\hline \multirow{2}{*}{ Distraction } & Pretest & 580.372 & 10.886 & 0.003 & \multirow{2}{*}{ Contemplation } \\
& Group & 495.487 & 9.294 & 0.005 & \\
& Pretest & 66.722 & 3.957 & 0.058 & \multirow{2}{*}{ Lost in thought } \\
& Group & 141.885 & 8.414 & 0.008 & \\
& Grotest & 51.498 & 5.052 & 0.034 & \multirow{2}{*}{0.312} \\
\hline
\end{tabular}

equal to $0.31\left(\eta^{2}=0.31\right)$. The adjusted mean scores of the components of rumination at posttest stage are listed in Table 6.

Hypothesis 2: Quality of Life-Based Therapy Is Effective on the Components of Rumination in Patients With Migraine.

To test the hypothesis, MANCOVA was used so that first, the homogeneity of covariance-variance matrices was investigated. According to Box's M test, covariance matrix was homogenous (Table 7). As shown in Table 8 and Table $9, P$ value was $<0.05$ and $\mathrm{f}_{(3,23)}$ was 2.55 , i.e., quality of life-based therapy was effective on the components of rumination at posttest stage.

The results of ANCOVA and f-test showed that after
Table 6. The Adjusted Mean Scores of the Components of Rumination at Posttest Stage in Mindfulness-Based Therapy and Control Groups

\begin{tabular}{lccc}
\hline \multirow{2}{*}{ Distraction } & Group & Mean Score & SD \\
& Experimental & 21.7687 & 1.901 \\
\multirow{2}{*}{ Contemplation } & Control & 30.033 & 1.901 \\
& Experiment & 9.522 & 1.069 \\
\multirow{2}{*}{ Lost in thought } & Control & 13.945 & 1.069 \\
& Experiment & 9.473 & 0.831 \\
\hline
\end{tabular}

Table 7. The Box's M Test Results on the Homogeneity of CovarianceVariance Matrices

\begin{tabular}{lcccc}
\hline Box's M & $\boldsymbol{F}$ & $\boldsymbol{d f}(\mathbf{1})$ & $\boldsymbol{d f}(\mathbf{2})$ & $\boldsymbol{P}$ \\
\hline 7.086 & 1.043 & 6 & 5680.302 & 0.395 \\
\hline
\end{tabular}

Table 8. The MANCOVA Results on Quality of Life-Based Therapy on the Components of Rumination

\begin{tabular}{llllllll}
\hline Test & $\begin{array}{l}\text { Source of } \\
\text { Variation }\end{array}$ & Value & $\boldsymbol{F}$ & $\boldsymbol{d} \boldsymbol{f}^{\mathrm{a}}$ & $\boldsymbol{d} \boldsymbol{f}^{\mathrm{b}}$ & $\boldsymbol{P}$ & Size of Effect \\
\hline $\begin{array}{l}\text { Wilks } \\
\text { lambda }\end{array}$ & Group & 0.75 & 2.556 & 3 & 23 & 0.08 & 0.25 \\
\hline${ }^{\mathrm{a} A s s u m e d ;}{ }^{\mathrm{b}}$ Error.
\end{tabular}

Table 9. The ANCOVA Results on the Effect of Quality of Life-Based Therapy on the Components of Rumination

\begin{tabular}{llcccc}
\hline & Variable & $\begin{array}{c}\text { Square } \\
\text { Sum }\end{array}$ & $\boldsymbol{F}$ & $\boldsymbol{P}$ Value & Effect Size \\
\hline \multirow{2}{*}{ Distraction } & Pretest & 741.752 & 16.287 & 0.001 & \multirow{2}{*}{0.198} \\
& Group & 281.566 & 6.179 & 0.020 & \\
\multirow{2}{*}{ Contemplation } & Pretest & 93.591 & 4.879 & 0.037 & \multirow{2}{*}{0.203} \\
& Group & 122.156 & 6.368 & 0.018 & \\
Lost in thought & Pretest & 53.795 & 4.938 & 0.036 & \multirow{2}{*}{0.227} \\
& Group & 79.956 & 7.340 & 0.012 & \\
\hline
\end{tabular}

In this study, $d f=1$, and thus sum of squares and mean square are equal.

removing the effect of pretest, the quality of life-based therapy was significantly effective on the posttest scores in the intervention group $\left(P<0.05, \mathrm{f}_{(1,29)}=6.18\right)$ and its effect was equal to 0.20 . Regarding contemplation, the effect of quality of life-based therapy was significant on the posttest scores $\left(P<0.05, \mathrm{f}_{(1,29)}=6.37\right)$ and the effect size was equal to $0.20\left(\eta^{2}=0.20\right)$. Regarding the component lost in thought, the effect of quality of life-based therapy was significant at posttest $\left(\mathrm{P}\right.$-value $\left.<0.05, \mathrm{f}_{(1,29)}=7.34\right)$ and the effect size was equal to $0.23\left(\eta^{2}=0.23\right)$. The adjusted mean scores of the components of rumination at posttest stage are listed in Table 10.

The mean scores of distraction, contemplation, and lost in thoughts at posttest stage significantly decreased in the quality of life-based therapy group in comparison with the control group.

The results of ANCOVA showed a difference between the effect sizes $\left(\eta^{2}\right)$ of the 2 therapies on rumination 
Table 10. The Adjusted Mean Scores of Components of Rumination at Posttest Stage

\begin{tabular}{lccc}
\hline & Group & Mean Score & SD \\
\hline \multirow{2}{*}{ Distraction } & Experimental & 21.7687 & 1.901 \\
& Control & 30.033 & 1.901 \\
Contemplation & Experiment & 9.522 & 1.069 \\
& Control & 13.945 & 1.069 \\
Lost in thought & Experiment & 9.473 & 0.831 \\
& Control & 13.460 & 0.831 \\
\hline
\end{tabular}

in patients with migraine, so that the effect size of the mindfulness-based cognitive therapy (0.312) was higher than that of the quality of life-based therapy $(0.226)$. To test the significance of the difference, Bonferroni's posthoc test was used in MANCOVA (Table 11).

According to the Bonferroni posthoc test results, the difference in intra-group effect on rumination between the 2 experimental groups was not significant $(P>0.05)$ (Table 12).

\section{Discussion}

Due to changes in urban life style and the effects of these changes such as more stressful life, the risk of various diseases including headache has increased. More than $90 \%$ of people experience headache at least once a way. Migraine headache is one of the most common causes of referrals to outpatient neurology clinics. It is a complicated and disabling disorder that might be affected by lifestyle, genetics, and environment. ${ }^{30}$

The effectiveness of mindfulness-based cognitive therapy and quality of life-based therapy on rumination in patients with migraine was studied in the current research. The results of ANCOVA on the distraction component after removal of pretest effect showed that the effect of mindfulness-based cognitive therapy was significant in our participants. This finding is consistent with results reported by Azargoon et al, Broderick and Patricia, and Rimz and Vingro. ${ }^{13,31,32}$

Rumination is a continuous mental engagement with a subject and is classified as a category of intentional thoughts that are concentered on a specific subject. These thoughts are repetitive and independent of environmental demands. ${ }^{33}$ Rumination may create negative mood effects on problem solving performance and motivation. In addition, it affects one's thoughts negatively and degrades problem solving capability. ${ }^{12}$ At this stage, the individuals overestimate potentially negative incidents, and because they consider themselves as responsible for the creation or prevention of negative thoughts and outcomes, they make attempts to control such thoughts. ${ }^{34}$

It is therefore essential to equip individuals with skills to act and think more constructively in facing problems and stressful situations. ${ }^{35}$ Cognitive therapy decreases motivation to adopt inefficient attitudes through modifying the contents of thoughts. Mindfulness represents a different relationship with thoughts. Rather than emphasizing bringing together events consistent or inconsistent with thoughts, this technique highlights individual's resistance to negative thoughts that is achieved through a different mindset, paying more attention, and concentration. It can be therefore concluded that mindfulness-based cognitive therapy affects the components of rumination in people with migraine.

The results of ANCOVA on the component distraction showed that after removing the effect of pretest, the effect of quality of life-based therapy was significant at posttest stage. Several studies reported that behavioral cognitive therapy decreased rumination. Their results are consistent with the results of this study except for the fact that this study. ${ }^{29,36,37}$ Patients with migraine suffer from negative automatic thoughts about their disease that continue as rumination and in turn intensify the symptoms and shorten the time interval between the migraine attacks. ${ }^{29}$ Psychotherapy based on the quality of life is a novel therapeutic method proposed by Frish. ${ }^{19}$ Over the past 2 decades, quality of life-based therapy has become one of the main topics in clinical practice by emphasizing the impacts of positive attention. ${ }^{38}$ To explain this finding, this therapy helps the patients through positively affecting life conditions, values, and expectations, which leads to adoption of more appropriate thoughts and establishment of more appropriate relationships with others. Thus, cognitive therapy based on quality of life can be effective on the components of rumination in patients with migraine.

Salkovskis argues that intrusive obsessive thoughts trigger specific types of automatic thoughts. Accordingly,

Table 11. Summary of the ANCOVA Results on the Effect of Mindfulness-Based Therapy and Quality of Life-Based Therapy on Rumination

\begin{tabular}{lllll}
\hline Variable & Treatment & $\boldsymbol{F}$ & $\boldsymbol{P}$ value & Effect Size \\
\hline \multirow{2}{*}{ Rumination } & Mindfulness-based cognitive therapy group & 11.784 & 0.002 & 0.312 \\
& Quality of life-based therapy group & 7.590 & 0.011 & 0.226 \\
\hline
\end{tabular}

Table 12. The Bonferroni's Post Hoc Test Results on the Intra-group Effects on Rumination in 2 Experimental Groups

\begin{tabular}{llllll}
\hline Variable & Group $(\mathrm{I})$ & Group $(\mathbf{J})$ & Difference in Mean Scores (I-J) & SD & $\boldsymbol{P}$ Value \\
\hline Rumination & Quality of life-based treatment & Mindfulness-based treatment & -3.640 & 4.979 & 0.471 \\
\hline
\end{tabular}


an intrusive thought leads to mood disorders when personal beliefs system finds the thought to be unacceptable and triggers negative automatic thoughts. In addition, feeling hyper-responsible and self-shaming are the main thought systems in migraine patients. ${ }^{39}$ Neutralization in the form of cognitive or behavioral arrangements is an attempt to attenuate feelings of hyper-responsibility and to avoid feeling ashamed. In light of this, interventions like the quality of life-based therapy and mindfulness-based cognitive therapy focus on determining and modifying the negative assessments of intrusive thoughts, modifying attitudes about hyperresponsibility, preventing the neutralization caused by this feeling, improving coping behaviors, and decreasing avoidance behaviors. Abdollahi et al reported that the behavioral cognitive therapy was effective in attenuating rumination in patients with migraine and compulsive obsessive disorder. ${ }^{9}$ Mansouri Shad et al observed that the behavioral cognitive therapy based on mentality was effective in improving migraine headache. ${ }^{40}$ Yousefi et al demonstrated that mentality -based cognitive therapy was effective on rumination and metacognitive beliefs in patients with obsessive disorder. ${ }^{41}$ The results of these studies are consistent with the present study. Limitations of our study include the small sample size that can challenge the validity of the findings and the use of selfreport instruments.

\section{Conclusion}

The results supported a substantial improvement of rumination and frequent intrusive thoughts thanks to the trainings designed to modify basic cognitions, replace negative and intrusive thoughts with positive thoughts, and remove intrusive thoughts avoidance behaviors through mindfulness-based cognitive therapy and quality of life-based therapy. In fact, changes in cognitive reactions to pain and modifying beliefs and expectations were the main mechanisms of improvement in the patients. Cognitions are related to emotional, physiological, and behavioral reactions. Therefore, people may change their behaviors through physiological and emotional responses.

\section{Ethical Approval}

This research was approved by at the Ethics Committee of Islamic Azad University of Mashhad (code: IR.IAU. MSHD.REC.1397.029).

\section{Competing Interests}

The authors declare no conflict of interest.

\section{Acknowledgements}

This article was derived from a $\mathrm{PhD}$ thesis at Islamic Azad University of Mashhad. The authors acknowledge the cooperation and assistance of all the loved ones who helped in conducting this research. In this study, all relevant ethical principles including the anonymity of the questionnaires, the informed consent for participation in the study, and the permission to withdraw from the study were observed.

\section{References}

1. Sadock BJ, Sadock VA. Kaplan Sadock's Synopsis of Psychiatry: Behavioral Sciences/Clinical Psychiatry. 10th ed. Philadelphia: Lippincott Williams \& Wilkins; 2007:467-477.

2. Coppola G, Pierelli F, Schoenen J. Habituation and migraine. Neurobiol Learn Mem. 2009;92(2):249-259. doi:10.1016/j.nlm.2008.07.006

3. Rockett FC, de Oliveira VR, Castro K, Chaves ML, Perla Ada S, Perry ID. Dietary aspects of migraine trigger factors. Nutr Rev. 2012;70(6):337-356. doi:10.1111/j.17534887.2012.00468.x

4. Fallahzade H, Alihaydari A, Hoseini H. Prevalence of migraine and tension headache in students of guidance schools in Yazd city, 2008. Razi Journal of Medical Sciences. 2010;17(76):52-61. [Persian].

5. Ebrahimi F, Najmi Varzaneh F, Mohammadi Y, Razaghi Jahromi S, Najmi Varzaneh F, Togha M. Migraine and tension type headaches among the medical staffs in Sina Hospital, Tehran, Iran. The Neuroscience Journal of Shefaye Khatam. 2018;6(2):25-30. doi:10.29252/ shefa.6.2.25. [Persian].

6. Lipton RB, Stewart WF, Von Korff M. The burden of migraine. A review of cost to society. Pharmacoeconomics. 1994;6(3):215-221. doi:10.2165/00019053-19940603000005

7. Schwaiger J, Kiechl S, Stockner $\mathrm{H}$, et al. Burden of atherosclerosis and risk of venous thromboembolism in patients with migraine. Neurology. 2008;71(12):937-943. doi:10.1212/01.wnl.0000325918.48056.75

8. D’Amico D, Libro G, Prudenzano MP, et al. Stress and chronic headache. J Headache Pain. 2000;1(Suppl 1):S49-S52. doi:10.1007/s101940070026

9. Abdollahi M, Arab Nejad M, Farzaneh S. The Effectiveness of Cognitive-Behavioral Therapy on Reducing Stomach Congestion in Migraine Patients with Obsessive Compulsive Disorder. 9th International Congress on Psychotherapy (Asian Summit on Cultural Values); 2015.

10. Abdollahi M. The Effectiveness of Cognitive-Behavioral Education on Reducing Rhombeism in Patients with Migraine with Obsessive Compulsive Disorder [thesis] Tehran: Allameh Tabatabaei University; 2011.

11. Martin LL, Tesser A. Toward a motivational and structural theory of ruminative thought. In: Uleman JS, Bargh JA, eds. Unintended thought. New York: Guilford Press; 1989:306-326

12. Papageorgiou C, Wells A. Depressive rumination: Nature, theory and treatment. New York: Wiley; 2004. doi:10.1002/9780470713853

13. Azargoon $\mathrm{H}$, Kajbaf MB, Molavi H, Abedi MR. The effect of mindfulness training on mental rumination and depression of the students of Isfahan University. Daneshvar Raftar. 2009;16(34):13-15. [Persian].

14. Kolotylo CJ, Broome ME. Predicting disability and quality of life in a community-based sample of women with 
migraine headache. Pain Manag Nurs. 2000;1(4):139-151. doi:10.1053/jpmn.2000.19344

15. Brown H, Newman C, Noad R, Weatherby S. Behavioural management of migraine. Ann Indian Acad Neurol. 2012;15(Suppl 1):S78-82. doi:10.4103/0972-2327.100018

16. Nicholson RA, Buse DC, Andrasik F, Lipton RB. Nonpharmacologic treatments for migraine and tensiontype headache: how to choose and when to use. Curr Treat Options Neurol. 2011;13(1):28-40. doi:10.1007/s11940010-0102-9

17. Rahimian Boogar I, Besharat MA. The effect of group mindfulness-based stress reduction program on the severity of fibromyalgia. Contemp Psychol. 2012;7(2):1528. [Persian].

18. Padash Z, Fatehizadeh M, Abedi MR, Izidikhah Z. Effect of quality of life based treatment on marital satisfaction. Journal of Research in Behavioral Sciences. 2012;10(5):363372. [Persian].

19. Frisch MB. Quality of Life Therapy: Applying a Life Satisfaction Approach to Positive Psychology and Cognitive Therapy. Trans, by Akram Khamseh. Ist ed. Wiley; 2005.

20. Rostami M, Abolghasemi A, Narimani M. The effectiveness of quality of life therapy on quality of life in maladjustment couples. Pajouhan Scientific Journal. 2016;15(1):19-27. doi:10.21859/psj-15013. [Persian].

21. Yousfpour N, Ahi Q, Nasri M. Psychotherapy based on improving quality of life on anxiety in patients with complicated mourning. Journal of Birjand University of Medical Sciences. 2015;22(2):145-153. [Persian].

22. Teasdale JD, Segal ZV, Williams JM, Ridgeway VA, Soulsby JM, Lau MA. Prevention of relapse/recurrence in major depression by mindfulness-based cognitive therapy. J Consult Clin Psychol. 2000;68(4):615-623. doi:10.1037/0022-006X.68.4.615

23. Kabat-Zinn J. Coming to our senses: Healing ourselves and the world through mindfulness. New York: Hyperion; 2003.

24. Davidson RJ, Kabat-Zinn J, Schumacher J, et al. Alterations in brain and immune function produced by mindfulness meditation. Psychosom Med. 2003;65(4):564-570. doi:10.1097/01.PSY.0000077505.67574.E3

25. Reibel DK, Greeson JM, Brainard GC, Rosenzweig S. Mindfulness-based stress reduction and health-related quality of life in a heterogeneous patient population. Gen Hosp Psychiatry. 2001;23(4):183-192. doi:10.1016/S01638343(01)00149-9

26. Najjarian B, Attari Y, Zargar Y. Compilation and scale validation for perfectionism. Journal of Faculty of Education and Psychology, Shahid Chamran University of Ahvaz. 1999;3(5):43-58. [Persian].

27. Shirzadi Bestoni A, Mehrabizadeh Honarmand M, Haghighi J. A study of simple and multiple relationship between perfectionism, trait-state anxiety and depression with migraine headache in students of Islamic Azad University of Ahvaz. Journal of Education and Psychology. 2003;9(3-4):109-126. [Persian].

28. Bagherinejad M, Salehi Fadardi J, Tabatabaei SM. Relationship between rumination and depression in a sample ofiranian students. Studies in Education \& Psychology. 2010;11(1):21-38. [Persian].

29. Tabibzadeh F, Sepehrian Azar F. The Effect of CognitiveBehavioral Therapy on the Resilience and Obsessive Rumination among Multiple Sclerosis (MS) Patients. Middle Eastern Journal of Disability Studies. 2017;7:1-5. [Persian].

30. Broderick PC. Mindfulness and coping with dysphoric mood: Contrasts with rumination and distraction. Cognit Ther Res. 2005;29(5):501-510. doi:10.1007/s10608-0053888-0

31. Rimes KA, Wingrove J. Pilot study of Mindfulness-Based Cognitive Therapy for trainee clinical psychologists. Behav Cogn Psychother. 2011;39(2):235-241. doi:10.1017/ s1352465810000731

32. Nolen-Hoeksema $\mathrm{S}$. The role of rumination in depressive disorders and mixed anxiety/depressive symptoms. J Abnorm Psychol. 2000;109(3):504-511. doi:10.1037/0021843X.109.3.504

33. Belloch A, Morillo C, Luciano JV, Garcia-Soriano G, Cabedo E, Carrio C. Dysfunctional belief domains related to obsessive-compulsive disorder: a further examination of their dimensionality and specificity. Span J Psychol. 2010;13(1):376-388. doi:10.1017/S1138741600003930

34. Hall DK, Pearson J. Resilience-giving children the skills to bounce back. Ontario: Voices for Children; 2003.

35. Joormann J. Differential effects of rumination and dysphoria on the inhibition of irrelevant emotional material: Evidence from a negative priming task. Cognit Ther Res. 2006;30(2):149-160. doi:10.1007/s10608-0069035-8

36. Norte CE, Souza GGL, Pedrozo AL, Mendonça-de-Souza ACF, Figueira I, Volchan E, et al. Impact of cognitivebehavior therapy on resilience-related neurobiological factors. Rev Psiquiatr Clin. 2011;38(1):43-45. doi:10.1590/ S0101-60832011000100009

37. Rahimian M. Health Clinical Psychology; Prevention, formulation and treatment. Tehran: Danzhe; 2008. [Persian].

38. Rajabi S, Abbasi Z. Epidemiology of Migraine Headaches and the Effectiveness of Fordis Behavioral Cognitive Behavioral Training on Reducing Migraine Symptoms and Increasing Happiness. Contemporary Psychology. 2013;2(9):89-100. [Persian]

39. Salkovskis PM. Cognitive-behavioural factors and the persistence of intrusive thoughts in obsessional problems. Behav Res Ther. 1989;27(6):677-682; discussion 683-674. doi:10.1016/0005-7967(89)90152-6

40. Mansourishad H, Togha M, Borjali A, Karimi R. Effectiveness of mindfulness-based cognitive-behavioral therapy on relieving migraine headaches. Arch Neurosci. 2017;4(4):e58028. doi:10.5812/archneurosci.58028

41. Yousefi E, Monireh Azadeh S, Majlesi Z, Salehi A. The Effectiveness of Mindfulness-Based Cognitive Therapy (MBCT) Intervention on Mental Ruminations, Metacognitive Beliefs, and Perfectionism in Patients with Obsessive-Compulsive Disorder in Isfahan Province. Int J Humanit Cult Stud. 2016;1943-1951. 